\title{
Sosialisasi Potensi Pengembangan Wisata Keramikan SuOH, KABUPATEN LAMPUNG BARAT
}

\section{${ }^{1}$ Linda Permata, ${ }^{2}$ Edo Kharisma Army, ${ }^{3}$ Angga Jati Widiatama, ${ }^{4}$ Muhammad Akbari Danasla, ${ }^{5}$ Hafid Zul Hakim, ${ }^{6}$ Fadli Nur Alfariezki, ${ }^{7}$ Binsar Sepriyadi Simarangkir}

\author{
1,2,4,5,6,7 Program Studi Teknik Pertambangan, Jurusan Teknologi Produksi dan Industri, Institut Teknologi \\ Sumatera, Lampung Selatan, Indonesia, ${ }^{3}$ Program Studi Teknik Geologi, Jurusan Teknologi Produksi dan \\ Industri, Institut Teknologi Sumatera, Lampung Selatan, Indonesia, ${ }^{6,7}$ Program Studi Sarjana Teknik \\ Pertambangan, Jurusan Teknologi Produksi dan Industri, Institut Teknologi Sumatera, Lampung Selatan, \\ Indonesia. \\ email: 'linda.permata@ta.itera.ac.id; '2edo.army@ta.itera.ac.id; 3 anggajatiwidiatama@gmail.com; \\ 4m.danasla@ta.itera.ac.id; ${ }^{5}$ hafid.hakim@ta.itera.ac.id; ${ }^{6}$ fadli.119370004@student.itera.ac.id; \\ binsar.119370065@student.itera.ac.id
}

\begin{abstract}
Geotourism has become well-known all around Indonesia as many places sustain distinctive characters - from the environment, aesthetics, culture, to residents. Keramikan, without exception, located in the borders of Kecamatan Suoh and Bandar Negeri Suoh has captured many local tourists by its exceptional geological and scientific importance: geothermal site. However, both tourists and the management have to struggle to enjoy this attractive geosite because of the lack of accessibility and amenity. Therefore, attempt measures were done to exaggerate the beauty of Keramikan geothermal site as a tourism site or geosite, including a) story-based socialization for locals that they can explain many 'whys' inside the site to the coming tourists, b) explaining through video the existing condition of accessibility and amenity as well as how the management can improve, c) poster making and distribution to start the health and safety awareness of the public, independent tourism organization, and Keramikan workers, and the government. Although attractions are undeniably appealing for stakeholders and tourists, the fact that accessibility and amenity cannot be improved due to regulation and license restrictions will be the downfall for the management. Therefore, this socialization is aimed to educate as well as to address the fundamental problems to the authority.
\end{abstract}

Keywords: geotourism, geosite, Keramikan Suoh, socialization

\begin{abstract}
Abstrak. Pesona Wisata Keramikan Suoh, Kabupaten Lampung Barat, erat kaitannya dengan peristiwa vulkanik yang hebat dan berlangsung hingga sekarang. Pengelolaan daerah wisata ini sudah dilakukan, namun perlu dorongan dan pengetahuan sebagai upaya meningkatkan daya tarik pengunjung. Upaya peningkatan daya tarik dilakukan dengan menyosialisasikan kejadian Kawah Keramikan dan sekitarnya dari sudut pandang geologi dan legenda setempat kepada media massa dan mitra, yaitu Kelompok Sadar Wisata, pengelola, komunitas ojek, Kecamatan Suoh, dan Dinas Pariwisata Lampung Barat. Upaya ini dilengkapi dengan pembuatan dan menyosialisasi video berisikan aspek atraksi, aksesibilitas dan amenitas. Mitra juga dibekali dengan manfaat-manfaat air panas serta himbauan kesehatan dan keselamatan kepada pengunjung. Mitra mengalami peningkatan pemahaman potensi dengan disosialisasikannya potensi pengembangan kepada komunitas ojek, pengelola, dan Kelompok Sadar Wisata dari segi atraksi. Namun, pemerintah, Dinas Pariwisata, dan pengelola Wisata Keramikan Suoh tidak dapat melakukan perbaikan akses dan pengembangan fasilitas pendukung (amenitas) karena perizinan. Selain observasi lapangan, metode wawancara juga dilakukan dengan hasil aksesibilitas dan amenitas yang kurang memadai akan mengurangi minat pengunjung walaupun Wisata Keramikan Suoh memiliki atraksi kuat. Solusi permasalahan ini tidak dapat langsung dijawab, tetapi potensi dan hal-
\end{abstract}


hal yang menghambat pengembangan wisata sudah diangkat ke pihak-pihak yang

berwenang.

Kata Kunci: geowisata, Keramikan Suoh, sosialisasi

\section{Pendahuluan}

Wisata Keramikan Suoh merupakan salah satu destinasi wisata yang berada di Kecamatan Suoh, Kabupaten Lampung Barat, Provinsi Lampung. Lokasi ini berjarak $197 \mathrm{~km}$ dari Institut Teknologi Sumatera yang berada di Kabupaten Lampung Selatan. Pada tahun 1933, terjadi peristiwa gempa besar disertai letusan freatik di wilayah Suoh. Gempa dan letusan ini menyebabkan terjadinya erupsi pada Gunung Ratu disertai asap tebal yang kelak melahirkan dua kawah di wilayah Suoh. Saat ini, peristiwa yang terjadi pada 1933 tersebut menjadi berkah tersendiri bagi masyarakat Suoh. Berkah tersebut antara lain dalam bentuk kesuburan lahan dan keindahan alam di wilayah Suoh, salah satunya Keramikan Suoh yang merupakan geoheritage potensial sebagai fondasi dalam pengembangan kawasan geowisata.

Pengembangan kawasan geowisata memerlukan sinergi antara pengelola, pemerintah, dan nilai unik kawasan wisata untuk mendapatkan loyalitas pengunjung/pelanggan (Robustin, Sularso, \& Suroso, 2018). Loyalitas pengunjung akan dipengaruhi banyak faktor, antara lain atraksi (attraction), keterjangkauan daerah (accessibility), dan nilai uang sesuai dengan fasilitas (amenity) serta kenyamanan di daerah wisata (Robustin et al., 2018). Observasi awal menunjukkan bahwa ketiga faktor utama, yaitu attraction, accessibility, amenity perlu diperbaiki guna memaksimalkan potensi pengembangan Wisata Keramikan Suoh. Faktor pertama, yaitu attraction (atraksi/daya tarik) dikelola sampai menjadi bentuk wisata alam kawah dan pemandian air panas tanpa dilengkapi informasi unik, ilmiah, maupun legenda yang beredar di masyarakat. Hal ini dinilai berpotensi untuk dibuat, disebarluaskan, dan dipergunakan sebagai media edukasi untuk pengelola sendiri (untuk meningkatkan kualitas tour guide) (Christie \& Mason, 2003), untuk Kelompok Sadar Wisata/PokDarWis (Prihantini, Lutfiyanto, Musoffan, \& Darwis, 2019), serta untuk pengunjung. Oleh karena itu, sebuah Pengabdian kepada Masyarakat (PkM) wisata Keramikan Suoh dibuat sebagai bentuk kontribusi kepada pengelola. Sedangkan, faktor kedua dan ketiga disampaikan dalam bentuk observasi dan kajian kepada pihak berwenang apabila ingin mengembangkan potensi geowisata.

Pengabdian kepada Masyarakat (PkM) wisata Keramikan Suoh, Kabupaten Lampung Barat ini bertujuan untuk menyosialisasikan daya tarik dan meningkatkan nilai jual wisata Keramikan Suoh yang merupakan geoheritage potensial dan sedang dikembangkan menjadi Kawasan Geopark Nasional dan Geopark UNESCO (Kementerian-ESDM, 2017). Hal ini dilakukan dengan melakukan sosialisasi pemahaman mengenai keunikan dari sudut pandang geologi serta potensi panas bumi di wilayah tersebut menggunakan bahasa yang mudah dipahami. Sehingga, masyarakat yang berada di sekitar wisata Keramikan Suoh lebih memahami nilai geologi maupun panas bumi yang terdapat pada kawasan tersebut. Berbekal hal tersebut, maka diharapkan masyarakat mampu menerapkan pendayagunaan lahan untuk objek wisata yang berbaku mutu lingkungan.

\section{Metode Ilmiah}

\section{Lokasi Pengabdian}

Pengabdian kepada Masyarakat (PkM) dilaksanakan di Wisata Keramikan Suoh, Kecamatan Suoh, Kabupaten Lampung Barat yang terdiri atas objek wisata Kawah Nirwana, Kawah Keramikan, 
beberapa kolam lumpur, dan danau. Istilah "keramikan" berasal dari fenomena yang terjadi di Kaldera Suoh berupa hamparan batuan yang mengeras dan mengerak menyerupai lantai "keramik". Kaldera Suoh merupakan kaldera aktif sehingga erupsi dapat terjadi setiap saat. Keberadaannya sebagai kantong (enclave) Taman Nasional Bukit Barisan Selatan (TNBBS) yang berada di sebuah dataran tinggi yang cukup luas (Gambar 1).

Kaldera Suoh terbentuk akibat adanya aktivitas vulkanik di wilayah Suoh yang dipengaruhi oleh aktivitas tektonik. Hal ini disebabkan oleh letak wilayah tersebut yang berada pada jalur sesar aktif Segmen Semangko, Blok Lampung, seperti diilustrasikan pada Gambar 1 (Natawidjaja, 2018). Danau Suoh dan Gunung Sekincau termasuk ke wilayah Bukit Barisan Sumatera, yaitu busur gunung api berumur Tersier-Kuarter (volcanic arc) yang terbentuk akibat subduksi lempeng IndoAustralia dibawah lempeng Eurasia yang dilewati oleh sesar besar Sumatera (Sumateran Fault Zone/SFZ) dengan arah Barat laut-Tenggara. Daerah ini didominasi bentuk topografi terjal dimana pada bagian tengahnya terdapat daerah rendahan yang merupakan Danau Suoh (Gambar 2). Bentuk topografi bagian barat daya daerah ini semakin landai hingga ke pantai barat Sumatera.

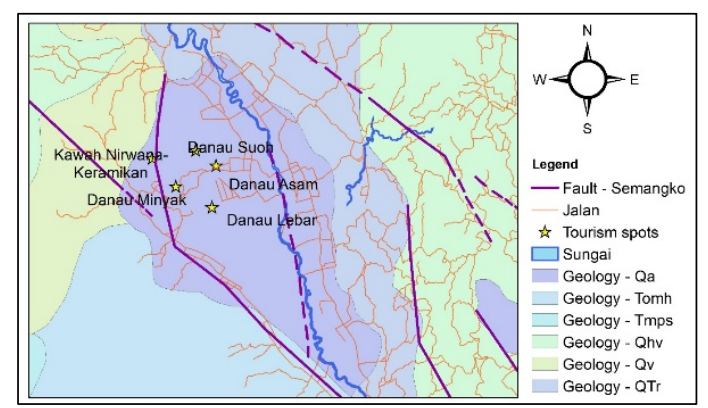

Gambar 1. Kondisi Geologi Lokasi Pengabdian, Peta Indeks yang Dimodifikasi dari Natawidjaja (2018); Menunjukkan Segmen Kumering (Bagian Utara dan Selatan) dan Segmen Semangko (Bagian Barat dan Timur)

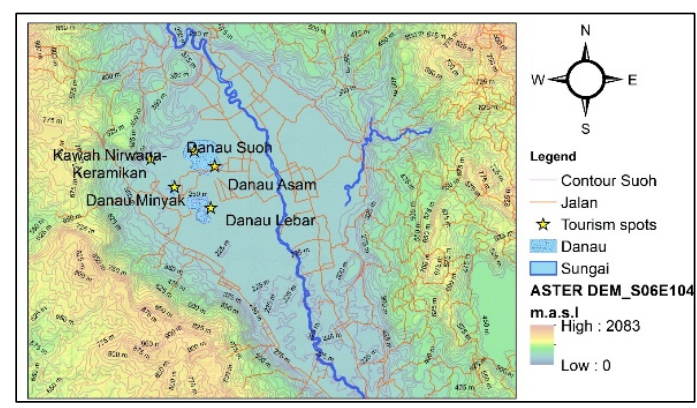

Gambar 2. Kondisi Geologi Lokasi Pengabdian Peta Kontur, Sungai, Serta Danau Objek Wisata.

Daerah penelitian ini memiliki beberapa formasi batuan endapan dari umur yang tua ke muda, diantaranya: Formasi Hulusimpang (Tomh) yang disusun oleh breksi gunungapi-lava-tuf, Formasi Seblat (Toms) yang disusun oleh perselingan batu pasir-batulempung -batulanau-gampingan, Formasi Ranau (QTr) yang disusun oleh breksi batuapung-tuf, batuan Gunung Api Kuarter Tua (Qv) yang disusun oleh lava andesit-basalt-tuf-breksi gunungapi dan batuan Gunungapi Kuarter Muda (Qhv) yang disusun oleh breksi-lava tuf. Danau Suoh merupakan kontak antara satuan Aluvium dengan produk Gunung Api Kuarter Tua, dimana banyak dijumpai manifestasi yang keluar dari bumi, sedangkan pada daerah Gunung Sekincau, manifestasinya banyak di jumpai di sekitar lereng gunung yang merupakan satuan batuan Gunung Api Muda Kuarter Sekincau.

Berdasarkan struktur geologinya, daerah ini didominasi oleh kelurusan berarah Barat laut-Tenggara dan merupakan segmen dari sesar besar Sumatera pada segmen Semangko. Danau Suoh merupakan cekungan yang terdapat pada bagian tengah yang terbentuk akibat sesar strike-slip dan bentuk pull-apart basin. Sesar atau patahan merupakan bidang lemah yang diduga menjadi jalur fluida/konduit (Iqbal \& Juliarka, 2019). 
Daerah Wisata Keramikan memiliki beberapa manifestasi permukaan yang unik meliputi kawah, mudpool, dan danau yang merupakan ciri khas lapangan panas bumi dengan sumber panas vulkanik (Stelling et al., 2016). Kawah Nirwana, Kawah Keramikan, Kawah Kopi Susu, dan Kawah Hitam adalah nama-nama kawah berdasarkan ciri - ciri yang membedakannya satu sama lain. Perbedaan inilah yang akan digali lebih dalam untuk meningkatkan atraksi Wisata Keramikan. Kolam lumpur atau mudpool tersebar di sekitar kawah-kawah dengan ukuran relatif jauh lebih kecil dari manifestasi lain.

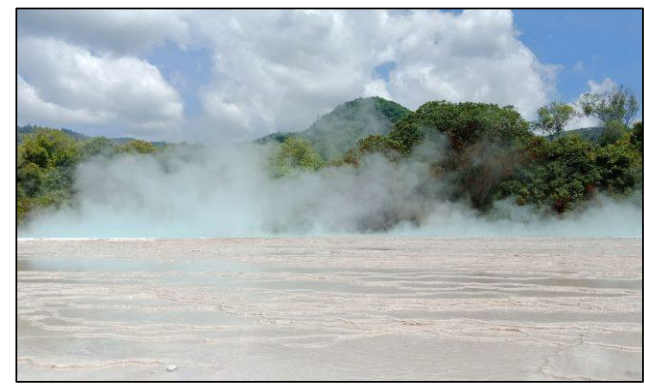

Gambar 3. Kawah Keramikan

\section{Analisis Situasi Daerah Wisata Keramikan Suoh}

Wilayah wisata Keramikan Suoh memiliki potensi yang besar sebagai geoheritage. Saat ini pemerintah daerah Kabupaten Lampung Barat sedang berupaya mengembangkan wilayah tersebut menjadi Kawasan Geopark Nasional dan Geopark UNESCO. Selain itu, wilayah ini juga diduga memiliki potensi panas bumi dalam lingkup reconnaissance dan manifestasi permukaan (Hochstein \& Sudarman, 2015). Akan tetapi, valuasi atas potensi panas bumi wilayah Keramikan Suoh ini tidak ditemukan; fakta bahwa wilayah wisata tumpang tindih dengan Taman Nasional Bukit Barisan Selatan (TNBBS) diduga membuat potensi panas bumi tidak dapat dieksploitasi.
Pemberdayaan lahan/potensi panas bumi yang cocok adalah sebagai tempat wisata (geowisata) dengan keunikan geologi khas manifestasi permukaan panas bumi. Pengembangan objek wisata ini dapat meningkatkan standar ekonomi dan sosial masyarakat lokal menuju pariwisata berkelanjutan (Ekasari, 2019). Oleh karena itu, pemahaman mengenai strategi pemasaran kreatif berbekal pengetahuan tentang pentingnya keunikan geologi dan kemampuan melihat peluang dari potensi/keunikan geologi yang ada perlu disosialisasikan untuk meningkatkan daya tarik dan nilai jual wisata Keramikan Suoh. Berbekal pengetahuan serta pemahaman tersebut, masyarakat diharapkan mampu menerapkan pendayagunaan lahan untuk objek wisata yang berbaku mutu lingkungan, membuat story telling yang menarik kepada calon pengunjung sehingga meningkatkan peluang kerja tour guide.

Faktor-faktor ini adalah pondasi bagi pengelola Wisata Keramikan Suoh untuk mendapatkan loyalitas pengunjung. Atraksi adalah inti daya tarik semua objek wisata, mulai dari atraksi alam seperti gunung, laut, flora, dan fauna (nature tourism), atraksi peninggalan sejarah, peninggalan purbakala (heritage tourism), seni dan budaya, penduduk lokal (cultural tourism). Ketercapaian daerah adalah halhal yang mendukung pengunjung sampai di tempat wisata dengan tingkat kemudahan beragam. Pengunjung sebaiknya ditunjang dengan moda transportasi yang mudah dijangkau (kendaraan umum atau kendaraan pribadi) dan kondisi jalan yang memadai. Dewasa ini, ketercapaian daerah juga termasuk jaringan yang memadai sebagai sarana telekomunikasi dan penunjang publikasi destinasi wisata. Amenitas dapat diterjemahkan sebagai fasilitas tambahan yang perlu ada untuk kenyamanan pengunjung, seperti penerangan, rumah 
makan, tempat ibadah, toilet umum, fasilitas kesehatan terdekat, toko cendera mata, dan fasilitas umum lainnya.

\section{Pemecahan Masalah}

Berdasarkan permasalahan yang dihadapi oleh mitra (pengelola, masyarakat, Kelompok Sadar Wisata/ Pokdarwis, pemerintah setempat), pengembangan potensi Wisata Keramikan Suoh diselesaikan dalam beberapa tahapan. Pengabdian kepada Masyarakat ini menitikberatkan pada tahapan awal yaitu peningkatan kualitas pengelola atas atraksi wisata Keramikan Suoh dan peningkatan kesadaran atas accessibility dan amenity yang kurang kepada pihak berwenang. Maka solusi yang dapat dilakukan beserta luaran kegiatan dijabarkan dalam Tabel 1.

Tabel 1

Rekapitulasi Jenis Kegiatan sebagai Solusi Permasalahan

\begin{tabular}{|c|c|c|c|}
\hline No & Solusi & & Luaran \\
\hline 1 & $\begin{array}{l}\text { Sosialisasi } \\
\text { sejarah } \\
\text { pembentukan } \\
\text { dan atraksi } \\
\text { geologi } \\
\text { Keramikan } \\
\text { Suoh }\end{array}$ & a) & $\begin{array}{l}\text { Peningkatan } \\
\text { pemahaman dan } \\
\text { keterampilan } \\
\text { masyarakat mengenai } \\
\text { atraksi utama Wisata } \\
\text { Keramikan Suoh (dari } \\
\text { segi geologi) melalui } \\
\text { media poster } \\
\text { Publikasi pada media } \\
\text { massa tentang pesona } \\
\text { alam Wisata } \\
\text { Keramikan Suoh untuk } \\
\text { membantu promosi }\end{array}$ \\
\hline 2 & $\begin{array}{l}\text { Sosialisasi } \\
\text { pemberdayaan } \\
\text { masyarakat } \\
\text { sekitar untuk } \\
\text { pemasaran } \\
\text { kreatif } \\
\text { menuju } \\
\text { geopark } \\
\text { nasional dan } \\
\text { geopark } \\
\text { UNESCO }\end{array}$ & a) & $\begin{array}{l}\text { Peningkatan } \\
\text { pemahaman dan } \\
\text { keterampilan } \\
\text { masyarakat mengenai } \\
\text { potensi, kelebihan, dan } \\
\text { kekurangan Wisata } \\
\text { Keramikan Suoh dari } \\
\text { segi ketercapaian } \\
\text { daerah dan amenitas } \\
\text { melalui media video. } \\
\text { Pembuatan poster yang } \\
\text { berisikan panduan } \\
\text { lokasi wisata, } \\
\text { himbauan kesehatan } \\
\text { dan keselamatan } \\
\text { kepada pengunjung } \\
\text { yang dapat digunakan }\end{array}$ \\
\hline
\end{tabular}

\begin{tabular}{|c|c|c|}
\hline No & Solusi & Luaran \\
\hline & & $\begin{array}{l}\text { oleh tour guide sebagai } \\
\text { pedoman. }\end{array}$ \\
\hline
\end{tabular}

\section{Khalayak Sasaran}

Kelompok sasaran untuk sosialisasi sejarah pembentukan Keramikan Suoh adalah Kelompok Sadar Wisata, pengelola, komunitas ojek, Kecamatan Suoh, dan Dinas Pariwisata Lampung Barat, serta media massa/masyarakat secara umum saat publikasi. Hal ini dilakukan untuk menambah nilai atraksi pada Wisata Keramikan Suoh. Sejarah pembentukan dikombinasikan dengan legenda masyarakat akan menarik minat calon pengunjung. Sedangkan, kelompok sasaran untuk sosialisasi strategi pemasaran dan pemberdayaan adalah masyarakat sekitar yang terlibat dalam pengelolaan Wisata Keramikan.

\section{Metode Pengambilan Data}

Metode pengambilan data untuk $\mathrm{PkM}$ antara lain survei lapangan dan wawancara warga. Oleh karena, situasi pandemi, tim $\mathrm{PkM}$ tidak mengumpulkan warga untuk mengisi survei, tetapi mengambil informasi mengenai atraksi, aksesibilitas, dan amenitas dari 2 orang pengelola (Gambar 4), 4 orang pengunjung (Gambar 5), dan 2 orang pemilik warung (Gambar 6) yang biasa dikunjungi. Wawancara dilakukan secara eksklusif sesuai pedoman perjalanan selama pandemi COVID-19 dari institusi dan dari kecamatan-kecamatan terkait (Kecamatan Suoh dan Kecamatan Bandar Negeri Suoh). Survei lapangan bertujuan untuk mengobservasi atraksi geologi yang menarik, sekaligus mempelajarinya supaya pengetahuan ini dapat disalurkan kepada masyarakat sekitar. 


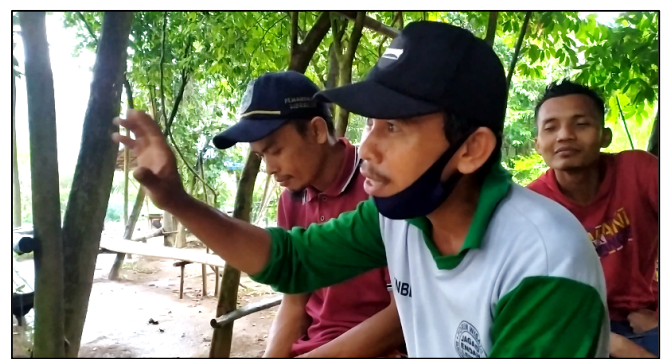

Gambar 4. Tahap Wawancara dengan Pengelola dan tour guide

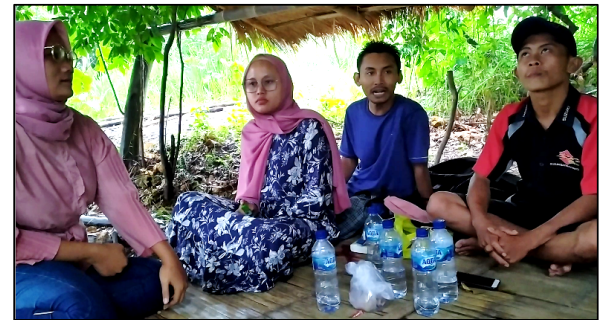

Gambar 5. Tahap Wawancara dengan Pengunjung

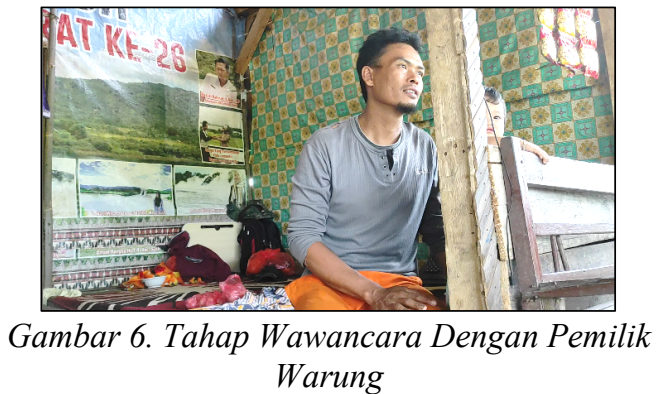

\section{Hasil dan Pembahasan}

Pengabdian kepada Masyarakat di daerah Wisata Keramikan Suoh memberikan hasil yang dapat dimanfaatkan oleh masyarakat sebagai sarana publikasi kepada calon pengunjung. Untuk itu, diperlukan kajian mendalam tentang atraksi utama Wisata Keramikan, analisis ketercapaian daerah dan fasilitas penunjang. Sosialisasi mengenai ketiga hal ini dilakukan melalui berbagai media seperti diuraikan pada sub-bab berikut ini.

\section{Atraksi Geologi Wisata Keramikan Suoh}

\section{Kawah Nirwana}

Kawah nirwana Suoh merupakan kaldera gunung api yang masih aktif. Kawah ini memiliki atraksi yang membedakan dengan kawah lainnya, yaitu sebuah geiser tepat dipusat kawah. Geiser tersebut memiliki debit intermiten setiap \pm 10 detik dengan ketinggian $>1$ meter. Observasi tidak dapat dilakukan pada jarak dekat dikarenakan pembuangan dari geiser tersebut memenuhi daerah dengan suhu sekitar $90^{\circ} \mathrm{C}$. Dari observasi yang dapat dilakukan, gas dari reservoir cukup cepat berkumpul di dekat permukaan sehingga interval debit cukup pendek. Gas-gas tersebut diduga dapat membentuk tekanan tinggi yang mengalahkan tekanan air sehingga terlepas ke atmosfer.

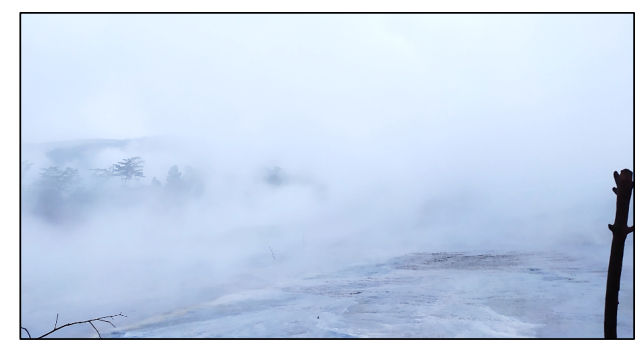

Gambar 7. Foto Kawah Nirwana

Saat observasi, Kawah Nirwana tidak dapat didokumentasikan dengan baik karena kondisi cuaca dan uap panas dari geiser menghalangi pemandangan (Gambar 7). Kawah Nirwana ini masuk kedalam bagian Taman Nasional Bukit Barisan Selatan yang memiliki mata air panas dengan cakupan manifestasi cukup luas diantaranya fumarol, mata air panas, dan ornamen travertine hasil endapan ion bikarbonat yang dihasilkan dari pelapukan batuan akibat cairan hidrotermal.

Atraksi Kawah Nirwana tidak hanya keindahan alam panas bumi yang telah disebutkan. Pengunjung juga dapat melepas 
lelah di kolam pemandian air panas yang berlokasi 10 meter dari Kawah Nirwana. Kolam yang berukuran sekitar 5x10 meter ini cukup untuk membuat pengunjung tak kunjung beranjak. Kolam pemandian air panas ini difasilitasi dengan kamar bilas, gazebo untuk kenyamanan pengunjung.

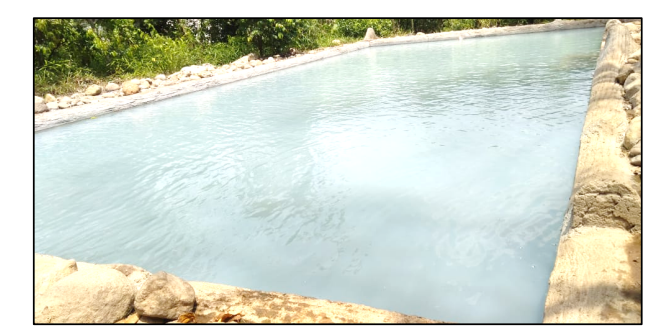

Gambar 8. Kolam pemandian/berendam di area Kawah Nirwana

\section{Kawah Keramikan}

Kawah Keramikan Suoh merupakan kawah manifestasi panas bumi berupa bentuk hamparan travertine yang mengeras dan tersebar di sekitar pusat kawah, sehingga membentuk seperti semen yang berlapis dan saling berdekatan dengan sumber air panas dari bumi. Pusat kawah yang ditandai dengan geyser memanjang kearah SE-NW dan memiliki lebar mencapai 20 meter, namun pengaruh alirannya menyebabkan pengendapan ion bikarbonat yang sangat luas mencapai lebar $>50$ meter.

Keramikan Suoh terbentuk dari pengendapan ion bikarbonat pada cairan hidrotermal dan pasir sulfur dari sumber panas Suoh yang mengendap selama bertahum-tahun dan membentuk seperti sebuah daratan (Gambar 9). Disebut Keramikan karena daratan ini memiliki warna yang putih kekuningan dan agak transparan.

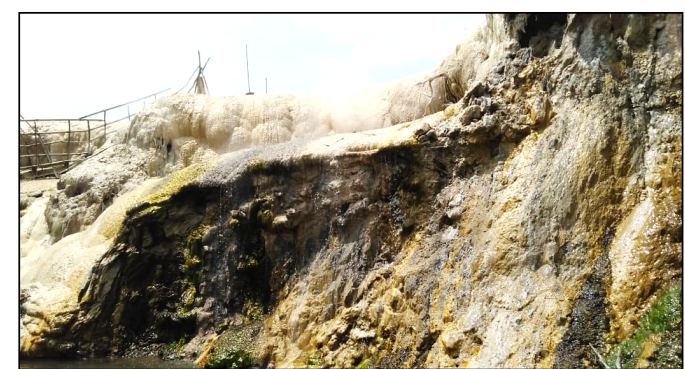

Gambar 9. Foto pengendapan ion bikarbonat Keramikan Suoh-Sekincau

Manifestasi panas bumi Kawah Keramikan dijuluki "Sisik Naga" secara khusus oleh warga dan pemandu wisata karena disebut-sebut bisa mengelupas seperti naga yang mengganti kulit. Manifestasi "Sisik Naga" ini merupakan tanda terdapatnya aktivitas batuan pijar/magma (sumber panas) yang memanaskan air tanah sehingga muncul sebagai mata air panas. Air yang muncul di permukaan membawa serta ion-ion sehingga saat air panas bertemu udara dingin di permukaan, terjadi pengendapan/kerak seperti keramik. Oleh karena itu, wisata ini dinamakan sebagai Kawah Keramikan atau seperti Keramik. Di Kawah Keramikan, proses ini berulangulang dari ribuan, ratusan ribu tahun yang lalu. "Keramik" yang berlapis-lapis dan bisa terlepas inilah yang disebut oleh lokal sebagai "Sisik Naga".

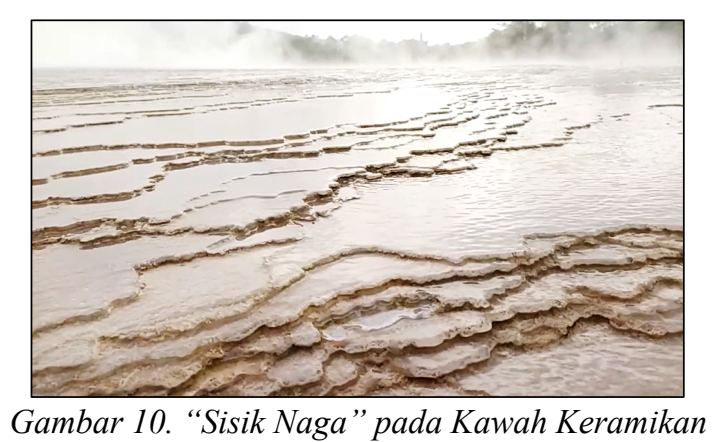

Observasi pada Kawah Keramikan memberikan hasil yang berbeda dari Kawah Nirwana dari segi geiser. Kawah 
Keramikan memiliki mata air panas/geiser yang bertekanan lebih rendah daripada geiser pada Kawah Nirwana. Hal ini ditunjukkan dengan interval debit yang lebih lama dan ketinggian geiser berkisar $30-50 \mathrm{~cm}$. Kondisi cuaca dan alasan keamanan, observasi hanya dapat dilakukan di sekitar pusat kawah sehingga jenis manifestasi tidak dapat dikonfirmasi lebih jauh. Uji keasaman (dengan kertas lakmus) juga dilakukan di Kawah Keramikan dan menunjukkan sifat lebih netral $(\mathrm{pH}$ 7-8) dibandingkan dengan Kawah Nirwana yang bersifat lebih basa ( $\mathrm{pH}$ 8-9). Hal ini dapat menjadi dasar penjelasan mengapa warna kekuningan (indikasi unsur sulfur) lebih banyak ditemui di Kawah Keramikan dibandingkan di Kawah Nirwana.

Selain kedua kawah tersebut, wisata ini juga memiliki dua kawah lainnya yang memiliki perbedaan jenis manifestasi, yaitu kolam lumpur, seperti Kawah Hitam dan Kawah Kopi Susu, serta kolam-kolam lumpur tak bernama.

\section{Kolam Lumpur "Kawah Hitam"}

Kawah Hitam merupakan salah satu manifestasi panas bumi yang berbentuk kolam lumpur yang berwarna coklat kehitaman. Kolam lumpur ini terbentuk dari hancuran batuan serta material organik yang tertimbun oleh batuan piroklastik hasil erupsi gunung api yang ada di sekitar Suoh. Kawah Hitam memiliki diameter $>15$ meter.

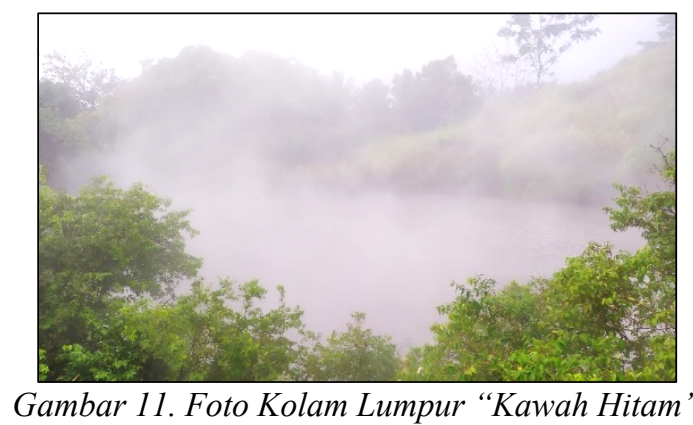

\section{Kolam Lumpur "Kawah Kopi Susu"}

Kawah Kopi Susu merupakan manifestasi panas bumi berupa kolam lumpur panas yang berwarna putih kecoklatan seperti campuran kopi dan susu. Kawah Kopi Susu ini berada di dekat Kawah Hitam namun memiliki karakterisitik yang sangat jauh berbeda. Hingga saat ini belum banyak penelitian yang mengungkapkan penyebab keberagaman variasi kawah di kawasan manifestasi panas bumi Suoh.

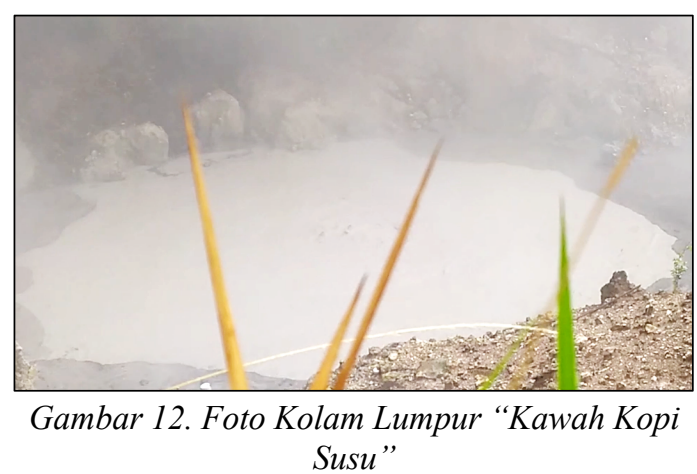

Tidak sampai disitu saja, hasil dari aktivitas vulkanik (gunung api) yang intensif juga menghasilkan danau-danau yang indah di sekeliling area wisata; Danau Lebar, Danau Asam, dan Danau Minyak.

\section{Danau Lebar}

Danau Lebar (Gambar 13) terletak di sebelah tenggara kolam lumpur "Kawah Kopi-Susu“ atau di selatan Danau Asam. Danau ini memiliki luas sekitar 67,8 Ha, merupakan danau paling luas yang membentuk hamparan air di kaki bukit hingga pemukiman setempat dan pada bagian tengah danau ini terdapat sebuah pulau. 


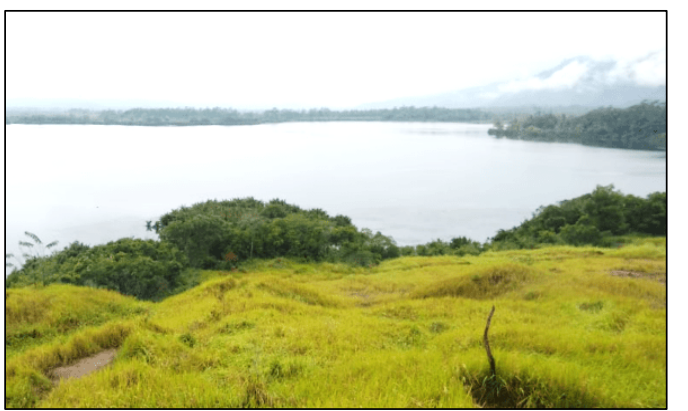

Gambar 13. Foto Danau Lebar Suoh-Sekincau (diambil dari arah barat daya)

\section{Danau Minyak}

Danau Minyak merupakan sebuah danau yang pada permukaannya memiliki kenampakan mengkilap seperti minyak, itulah alasan dari pemberian nama Danau Minyak. Danau ini memiliki luas sekitar 10 Ha. Selain memiliki bau seperti minyak tanah, menurut warga sekitar bau minyak di danau ini mulai menghilang dan lapisan air di atas tidak bercampur dengan lapisan yang ada di bawahnya.

\section{Danau Asam}

Danau asam merupakan danau yang memiliki $\mathrm{pH}<7$. Informasi yang beredar di masyarakat menyebutkan bahwa rasa danau tersebut asam, itulah alasan danau ini disebut dengan Danau Asam. Danau ini memiliki luas sekitar 121,1 Ha dan terdapat butir pasir kuning di sekitar tepi danau.

\section{Danau Belibis}

Danau Belibis memiliki luas sekitar dua Ha. Disebut Danau Belibis karena danau ini merupakan jalur migrasi burung belibis dan selalu dipenuhi burung belibis yang sedang berimigrasi.

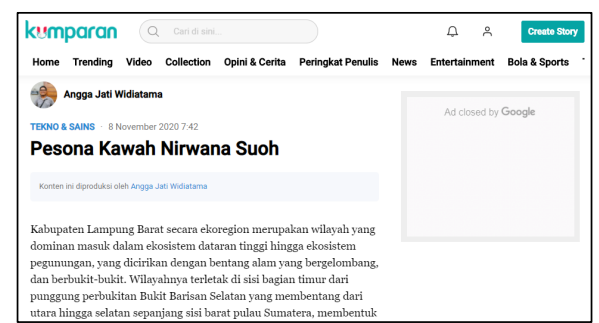

Gambar 14. Publikasi pada media massa

Sumber: (https://kumparan.com/angga-jati-widiatama/pesona kawah-nirwana-suoh-1uXxk6rkZLu)

Hasil observasi tim tersebut disalurkan ke media massa (Gambar 14) dan berhasil dipublikasikan pada tanggal 8 November 2020. Selain disalurkan melalui media massa, hasil observasi juga dirangkum ke dalam poster dengan menjual kelebihan komersial, seperti berendam dengan air panas yang mengandung mineral karbonatan, bagus untuk kesehatan kulit.

\section{Analisis Ketercapaian Lokasi (Accessibility) dan Fasilitas Penunjang (Amenity)}

Daya tarik utama Wisata Keramikan Suoh menjadi inti dari lokasi geowisata yang akan diberdayakan oleh masyarakat. Namun, hal ini belum cukup didukung oleh faktor ketercapaian lokasi dan fasilitas penunjang di sekitar lokasi wisata. Meskipun tidak mengurangi nilai dari keunikan geologi setempat, analisis kondisi aktual di lapangan dan saran pengembangan perlu disampaikan untuk perubahan yang lebih baik.

Lokasi Wisata Keramikan Suoh dapat ditempuh dengan kendaraan pribadi melalui dua jalur, yaitu melalui Jalan Lintas Barat Sumatera (melewati Jl. Semaka-Suoh di Suka Marga) dan Jalan Lintas Sumatera dengan jarak tempuh yang lebih jauh $( \pm 270$ $\mathrm{km})$ dalam waktu \pm 6 jam. Keduanya memiliki alternatif Jalan tol sampai kawasan Suka Marga. Tidak banyak pilihan untuk kendaraan umum, alternatif paling baik untuk kendaraan umum adalah bus dan 
jasa travel. Pengunjung harus mengetahui bahwa medan terjal dan jalan pegunungan berliku-liku harus dilewati untuk mencapai lokasi Wisata Keramikan Suoh. Hal ini diharapkan menjadi pertimbangan untuk memilih moda transportasi dan waktu kunjungan karena rawan kecelakaan, seperti kecelakaan yang terjadi tepat saat tim pengabdian melakukan observasi ke lokasi ("Mau ke Suoh, Bus Pembawa Rombongan Pengantin Masuk Jurang di Lambar," 2020). Peristiwa naas ini sempat tertangkap dalam dokumentasi tim di YouTube channel Teknik Pertambangan ITERA pada link https://youtu.be/c0hcx56p474.

Waktu kunjungan menjadi sangat penting karena akses jalan menuju kawah tidak sepenuhnya beraspal dan rata. Terdapat beberapa titik yang berubah menjadi jalan berlumpur berbatu yang sangat licin sehingga kendaraan, khususnya roda empat, mudah tergelincir, terperosok, dan tersangkut batu besar (Gambar 15). Hal ini umum terjadi setelah hujan deras atau hujan terus-menerus pada musim hujan. Pada kondisi demikian, warga lokal menyediakan jasa derek menggunakan hard top sehingga kendaraan roda empat dapat lolos dari jalan berlumpur dari kedua jalur, namun bukan tanpa risiko kendaraan lecet. Tarif jasa derek menggunakan hard top adalah $\mathrm{Rp} 50.000,-/$ mobil satu kali derek. Hasil wawancara dengan warga sekitar menyebutkan bahwa jalan berlumpur terjadi di beberapa titik termasuk alternatif jalan menuju Suoh sehingga jasa hard top hanya terbatas satu kendaraan per lokasi.

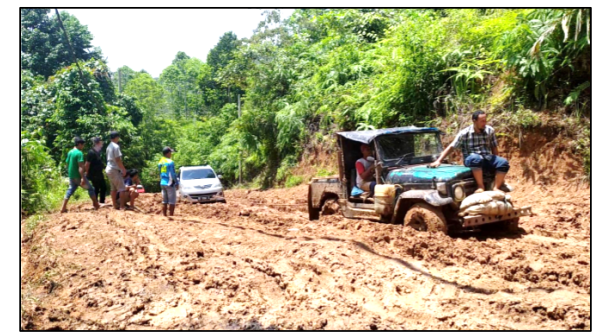

Gambar 15. Kondisi akses menuju daerah wisata; hard top yang sedang menderek mobil

Lingkungan sekitar jalan berlumpur merupakan area hutan dan jurang, tanpa pemukiman warga dan tanpa penerangan selain lampu kendaraan (Gambar 16). Oleh karena itu, pengunjung harus bijaksana memilih waktu kunjungan dan waktu pulang karena bilamana jasa hard top berhenti tidak dapat diprediksi; jasa dapat beroperasi sampai tengah malam apabila hujan belum terlalu intens, jasa berhenti sekitar pukul 18.00 WIB apabila lalu-lalang transportasi tinggi dan melebihi kapasitas hard top dalam satu hari operasi. Skenario kedua sangat mungkin terjadi ketika musim hujan. Oleh karena itu, pengunjung harus merencanakan dengan bijaksana apabila ingin berkunjung pulang-pergi ke Wisata Keramikan Suoh.

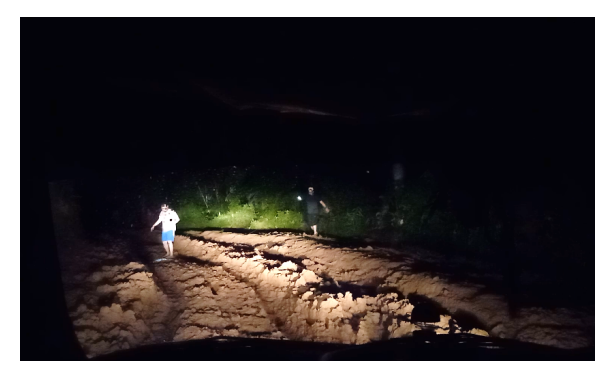

Gambar 16. Kondisi akses jalan berlumpur di malam hari

Masyarakat setempat memiliki tips bagi pengguna kendaraan pribadi untuk memasang rantai di setiap ban mobil agar tidak tergelincir. Hal ini juga dilakukan oleh warga sekitar pengguna kendaraan roda dua. Kendaraan roda dua juga merupakan alternatif transportasi menuju 
kawasan wisata, namun tidak praktis dan tidak aman bagi pengunjung yang berasal dari luar Lampung Barat dan sekitarnya. Pengunjung yang tidak dapat kembali karena jasa derek tidak ada, dapat kembali ke sekitar kawasan wisata karena terdapat beberapa pemukiman untuk mengamankan diri. Fasilitas yang ada berupa toko kelontong, warung makan, tempat beristirahat, dan tempat ibadah sederhana (Gambar 17). Tidak ada tempat penginapan disekitar kawasan wisata karena batasan aturan pemerintah daerah yang tidak mengizinkan bangunan penginapan permanen. Tidak ada fasilitas kesehatan maupun toko cinderamata yang biasanya menarik perhatian pengunjung setelah berwisata. Dengan tambahan informasi ini, pengunjung diharapkan bersiap siaga pula, selain memilih waktu kunjungan dengan bijaksana.

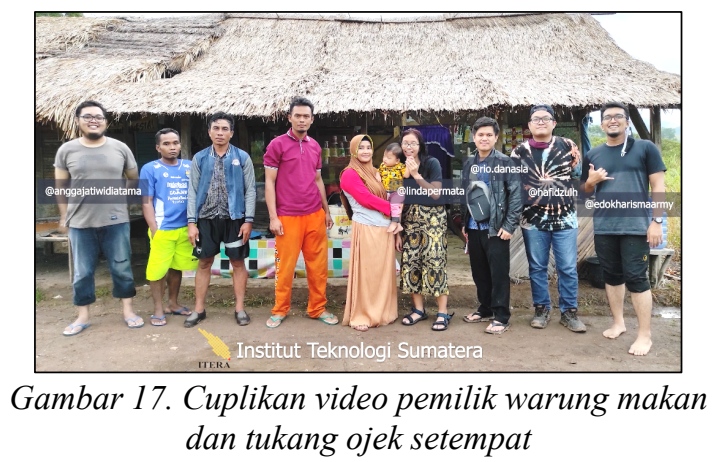

Uraian di atas menjelaskan ketercapaian lokasi wisata dan fasilitas penunjang untuk kenyamanan pengunjung. Dapat disimpulkan bahwa lokasi dapat dicapai oleh pengunjung paling nyaman menggunakan moda transportasi roda empat atau roda dua pada musim kemarau agar terhindar dari jalan berlumpur dan terhindar dari risiko kendaraan lecet karena diderek.

Kunjungan di musim kemarau juga mengurangi risiko kehilangan waktu liburan karena tertunda hujan, mengurangi risiko terjebak di kawasan wisata satu malam karena mobil derek sudah tidak beroperasi dan tidak ada tempat penginapan. Fasilitas penunjang lain yang ada di kawasan wisata antara lain SPBU, warung makan, jasa ojek dari gerbang utama ke titik lokasi, toko kelontong. Tidak ada fasilitas penunjang lain seperti penerangan, fasilitas kesehatan, bank atau ATM, dan pos penjagaan untuk keadaan darurat.

\section{Sosialisasi Atraksi Geologi Wisata Keramikan Suoh dan Peningkatan Pemahaman mengenai Ketercapaian Lokasi (Accessibility) dan Fasilitas Penunjan (Amenity) untuk Pemberdayaan Masyarakat}

Sosialisasi atraksi geologi Wisata Keramikan Suoh dilakukan melalui media massa Kumparan dan pembuatan poster seperti dijelaskan pada sub-bab. Poster tersebut didistribusikan kepada pihak kecamatan, Kelompok Sadar Wisata (POKDARWIS), Dinas Pariwisata Kab. Lampung Barat, pihak pengelola dan warga setempat untuk ditempel disekitar gerbang dan loket tiket agar pengunjung mendapatkan informasi tambahan.

Hasil wawancara dari beberapa pihak menyebutkan bahwa permasalahan krusial yang dihadapi untuk mengelola daerah wisata ini adalah aksesibilitas dan amenitas. Warga menyebutkan bahwa akses yang bagus masih belum ada untuk menjangkau daerah ini (Gambar 15). Pengunjung berpendapat bahwa Wisata Keramikan Suoh sangat indah terutama kolam pemandian air panas, namun dengan akses seperti ini pengunjung tidak akan merekomendasikan kepada teman atau saudara. Hal ini menjadi bahan pemikiran tim PkM untuk menyuarakan masalah ini kepada pihak berwenang. Penyaluran suara dilakukan dengan pembuatan video berisi 
atraksi, aksesibilitas, dan amenitas (https://youtu.be/c0hcx56p474).

Video ini kemudian disosialisasikan kepada pemerintah, masyarakat, dan dinas pariwisata untuk merealisasikan maksud tim (Gambar 18). Video ini tidak hanya berisi kritik, namun juga sejarah pembentukan Wisata Keramikan. Dengan demikian, warga/tour guide bisa memanfaatkan pengetahuan ini untuk bercerita kepada pengunjung.

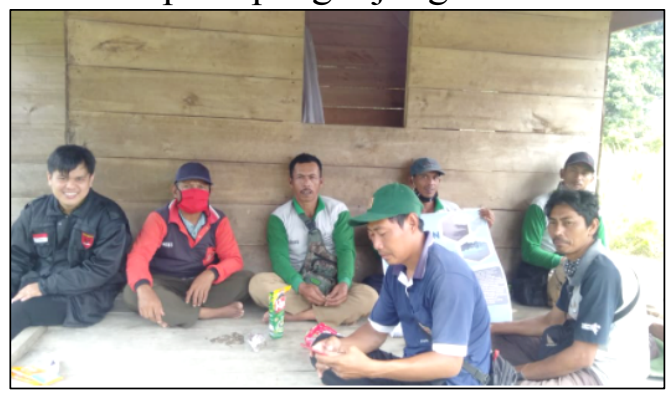

Gambar 18. Sosialisasi kepada pengelola (komunitas ojek, warung, dan tour guide)

Guna meningkatkan pemahaman masyarakat untuk pemberdayaan berkelanjutan, sosialisasi mengenai manfaat kolam pemandian dan aturan keselamatan wisata panas bumi juga dilakukan dengan membuat dan menyebarkan poster ke warung, pengelola (tour guide), komunitas ojek, Kecamatan Suoh, dan Dinas Pariwisata Lampung Barat (Gambar 19,20,21). Kegiatan ini mendapatkan respon yang baik dari mitra karena bentuk luaran yang dihasilkan.

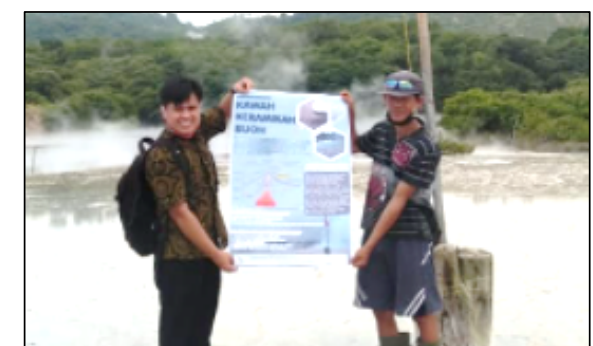

Gambar 19. Sosialisasi dan penyerahan poster kepada mitra) tour guide

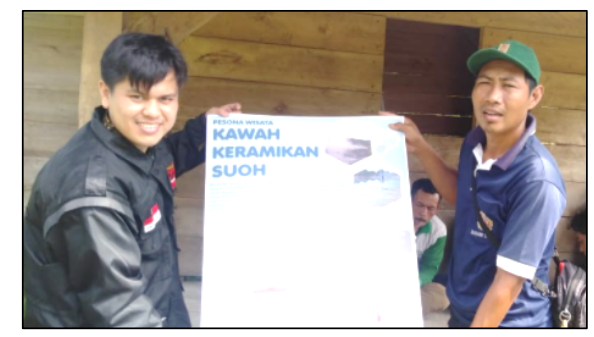

Gambar 20. Sosialisasi dan penyerahan poster kepada mitra pengurus PokDarWis

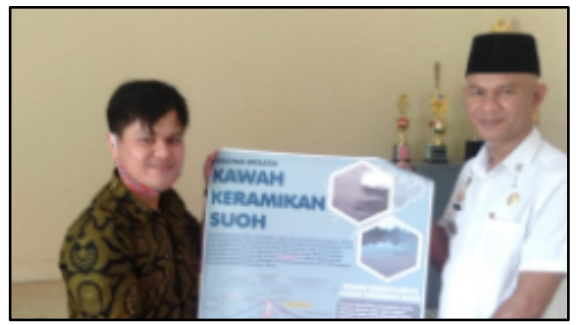

Gambar 21. Sosialisasi dan penyerahan poster kepada mitra Dinas Pariwisata

Sosialisasi poster ini berfokus kepada manfaat air panas Wisata Keramikan Suoh, yaitu baik untuk regenerasi kulit, menyembuhkan penyakit kulit, dan merawat kulit dengan membersihkan pori-pori, kulit terlihat lebih sehat dan cerah. Poster tersebut juga berisi himbauan kepada pengunjung agar mematuhi aturan kesehatan dan keselamatan, diantaranya menyadari bahwa kawah masih aktif, melaporkan keberadaan pengunjung kepada petugas atau pengelola, selalu menggunakan alas kaki karena suhu tinggi $\quad>60^{\circ} \mathrm{C} \quad$ (menghindari luka bakar/melepuh dan kondisi kawah yang tidak stabil), menjauh jika merasa pusing/mual karena terpapar gas belerang, serta memahami jalur evakuasi.

Pemberdayaan masyarakat yang dapat dipetik dari pelaksanaan Pengabdian kepada Masyarakat Wisata Keramikan Suoh antara lain:

a. Penyewaan loker dan alat pelindung diri minimal sepatu boots. Hal ini bertujuan untuk menjaga keselamatan pengunjung selama 
fasilitas kesehatan dan alat-alat pertolongan pertama belum ada. Penyewaan alat pelindung diri dapat dilengkapi dengan penyewaan jas hujan untuk membuat pengunjung nyaman walaupun dalam keadaan hujan.

b. Penyewaan peralatan bilas untuk pengunjung yang memiliki tujuan utama berendam di kolam pemandian. Kamar bilas sudah disediakan sehingga kelengkapan ini dapat membuat pengunjung nyaman dan memberdayakan masyarakat (penjualan alat mandi).

c. Pembaharuan jalan setapak di wilayah kawah Nirwana dan Kawah Keramikan. Pengunjung akan berisiko terkena air panas untuk waktu yang lama apabila tidak ada jalan setapak yang lebih tinggi dari muka air seperti pada Gambar 22. Akan tetapi, jalan setapak ini hanya dibuat dari kayu dan memiliki tinggi tidak berbeda jauh dengan muka air panas. Selain itu, perlu dibangun dua jalur untuk lalu-lalang.

d. Pemasangan papan-papan informasi yang berisi informasi suhu udara, suhu air, pengetahuan tentang manifestasi permukaan lapangan panas bumi secara lebih ilmiah di dekat masing-masing manifestasi. Hal ini dapat membantu tour guide, yaitu warga sekitar untuk memberikan kisah-kisah daerah wisata dan memberikan informasi keamaan kepada pengunjung.

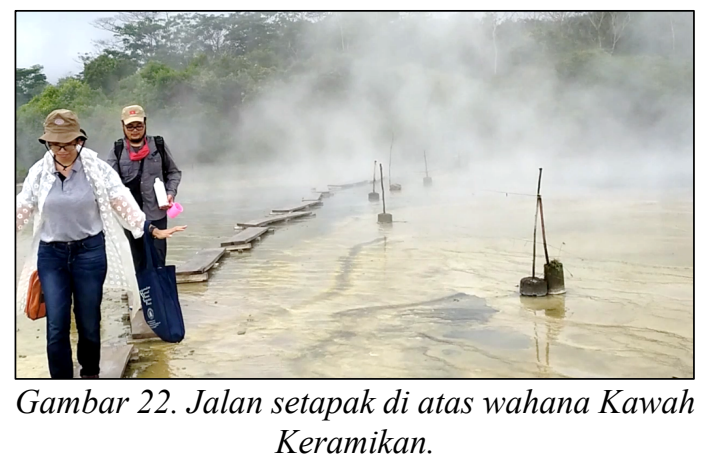

\section{Kesimpulan dan Saran}

(PkM) Pengabdian kepada Masyarakat menghasilkan beberapa luaran yakni video yang berisi atraksi, aksesibilitas, dan amenitas daerah wisata untuk bahan pengetahuan mitra dan pihak berwenang. Video ini diharapkan mampu menyuarakan permasalahan aksesibilitas yang sangat krusial saat ini. Luaran poster mengandung informasi kejadian daerah wisata, manfaat air panas Keramikan, serta himbauan kesehatan dan keselamatan pengunjung. Hal ini dapat meningkatkan kemampuan pengelola (khususnya tour guide), dan mencegah kecelakaan (luka bakar karena air panas). $\mathrm{PkM}$ ini disambut dan direspon dengan sangat baik oleh pemerintah maupun masyarakat dan diharapkan membuahkan hasil yang positif. Pemberdayakan masyarakat dapat dilakukan berdasarkan zero accident geothermal site, diantaranya dengan cara membuka usaha baru penyewaan sepatu boots, jas hujan, jasa toiletaries dalam pemandian, sampai dengan pembaharuan jalur pejalan kaki di sekitar kawah panas.

\section{DAFTAR PUSTAKA}

Christie, M. F., \& Mason, P. A. (2003). Transformative tour guiding: Training tour guides to be critically reflective 
practitioners. Journal of Ecotourism, 2(1), 1-16.

Ekasari, A. M. (2019). Menilai Kelayakan Pengembangan Situ-Situ Di Kabupaten Bekasi sebagai Obyek Destinasi Wisata. ETHOS: Jurnal Penelitian Dan Pengabdian Kepada Masyarakat, 7(2), 244-253.

Hochstein, M. P., \& Sudarman, S. (2015). Indonesian Volcanic Geothermal Systems. World Geothermal Congress 2015, (April), 11.

Iqbal, M., \& Juliarka, B. R. (2019). Analisis

Kerapatan Kelurusan (Lineament Density) sebagai indikator tingkat permeabilitas di Lapangan Panasbumi Suoh-Sekincau, Lampung. Journal of Science and Applicative Technology, $3(2)$, 61-67. https://doi.org/10.35472/x0xx0000

Kementerian-ESDM. (2017). Potensi Panas Bumi Indonesia (Jilid.1; PSDMBP \& BadanGeologi, eds.). Jakarta: Direktorat-Panas-Bumi, Dirjen-EBTKE.

Mau ke Suoh, Bus Pembawa Rombongan Pengantin Masuk Jurang di Lambar. (2020). Detik Lampung. Retrieved from http://detiklampung.com/read/13257/ma u-ke-suoh-bus-pembawa-rombonganpengantin-masuk-jurang-di-lambar

Natawidjaja, D. H. (2018). Updating active fault maps and sliprates along the
Sumatran Fault Zone, Indonesia. IOP Conference Series: Earth and Environmental Science, 118(1). https://doi.org/10.1088/17551315/118/1/012001

Prihantini, C. I., Lutfiyanto, L., Musoffan, M., \& Darwis, D. (2019). Pemberdayaan Kelompok Sadar Wisata (Pok-Darwis) sebagai Penggerak Kemajuan Wisata Edukasi Jumiang. ETHOS: Jurnal Penelitian Dan Pengabdian Kepada Masyarakat, 7(2), 336-341.

Robustin, T. P., Sularso, R. A., \& Suroso, I. (2018). The Contribution of Tourist Attraction, Accessibility and Amenities in Creating Tourist Loyalty in Indonesia. Journal of Business and Economics Review, 3(4), 92-98.

Stelling, P., Shevenell, L., Hinz, N., Coolbaugh, M., Melosh, G., \& Cumming, W. (2016). Geothermal systems in volcanic arcs: Volcanic characteristics and surface manifestations as indicators of geothermal potential and favorability worldwide. Journal of Volcanology and Geothermal Research, 324(May), 5772 .

https://doi.org/10.1016/j.jvolgeores.201 6.05.018. 